\title{
Predictors of outcomes in patients with gastric cancer treated with contemporary multimodality strategies - a single institution experience
}

\author{
Tuyen Hoang ${ }^{1}$, Michelle Park ${ }^{2}$, Darryl Hiyama ${ }^{3}$, Farshid Dayyani ${ }^{4}$ \\ ${ }^{1}$ Institute for Clinical and Translational Science, ${ }^{2}$ Department of Medicine, University of California in Irvine, Irvine, CA, USA; ${ }^{3}$ Department of \\ General Surgery, University of California in Los Angeles, Los Angeles, CA, USA; ${ }^{4}$ Department of Medicine, Division of Hematology and Oncology, \\ University of California in Irvine, Irvine, CA, USA \\ Contributions: (I) Conception and design: All authors; (II) Administrative support: None; (III) Provision of study materials or patients: None; (IV) \\ Collection and assembly of data: All authors; (V) Data analysis and interpretation: All authors; (VI) Manuscript writing: All authors; (VII) Final \\ approval of manuscript: All authors. \\ Correspondence to: Tuyen Hoang, PhD. 843 Health Sciences Road, Irvine, CA 92697, USA. Email: tuyenh1@uci.edu.
}

Background: While gastric cancer is a leading cause of cancer-related mortality in Eastern Europe and Asia, it is less common in the United States. Recommendations regarding optimal treatment of nonmetastatic gastric cancer with regard to type and extent of surgery, choice and sequence of chemotherapeutic agents, and use of radiation therapy vary somewhat depending on geographic location. There is paucity in the literature for direct comparison of various practices. To determine how variability in treatment practices affects patient outcomes, we conducted a retrospective study in patients with gastric cancer who had multimodality treatment for non-metastatic gastric cancer.

Methods: We gathered clinical data (patient demographics, pathology reports, type of surgical intervention, chemotherapy, and radiation therapy) for patients diagnosed with gastric adenocarcinoma who underwent gastrectomy at five sites from 2010-2017 using Electronic Health Records and California Cancer Registry databases. Medical chart reviews were conducted to validate patient outcomes. We performed multivariate Cox regression analyses to determine predictors for cancer recurrence and survival. We also performed logistic regression analyses to determine predictors of positive resection margins and hospitalization.

Results: One hundred and sixteen patients met eligibility criteria to be included. Mean age was $65.7 \pm$ 11.6 years. About $65.5 \%$ were male. The most common ethnicities were Asian $(44.0 \%)$ and Caucasian (37.9\%). About $58.6 \%$ of the patients had localized disease (defined as pT1-3, pN0) and the remaining $41.4 \%$ had loco-regional disease (i.e., pT4 or pN+). About $41.4 \%$ of the tumors were diffuse, $27.6 \%$ intestinal, $12.0 \%$ mixed, and 19.0\% unknown histology. Surgery included laparoscopic (94.8\%) and open gastrectomy (5.2\%). Chemotherapy and radiation therapy were given in $51.7 \%$ and $19.0 \%$ of the patients, respectively. After a median follow-up time of 19 months after gastrectomy, $16.4 \%$ of patients had recurrence and $19.8 \%$ had died. Patients who had loco-regional tumors were more likely to have recurrence and death than those who had localized tumors (hazard ratios $=7.0, \mathrm{P}=0.0228$ for recurrence and hazard ratios $=3.3$, $\mathrm{P}=0.0160$ for death). Positive resection margins were seen in $9 \%$ of the patients and were associated with diffuse histology (odds ratio =6.6, $\mathrm{P}=0.0207$ ). Hospitalization within six months of gastrectomy was seen in $22 \%$ of the patients. Peri-operative chemotherapy was the only significant predictor for re-hospitalization (odds ratio $=3.5, \mathrm{P}=0.0415$ ).

Conclusions: In this contemporary cohort of patients with localized gastric cancer, only the pathological stage was significantly associated with survival while positive resection margins were associated with diffuse histology. Closer monitoring of patients undergoing perioperative chemotherapy within 6 months of surgery is warranted based on our observation of higher rate of re-hospitalization.

Keywords: Gastric cancer; prognostic factors; gastrectomy; multimodality treatment 
Submitted Oct 30, 2018. Accepted for publication Jan 11, 2019.

doi: 10.21037/jgo.2019.01.08

View this article at: http://dx.doi.org/10.21037/jgo.2019.01.08

\section{Introduction}

Gastric cancer is the fifth most common malignancy and the third leading cause of cancer mortality worldwide (1). While gastric cancer is a leading cause of cancer-related mortality in Eastern Europe and Asia, it is less common in the United States. Recommendations regarding optimal treatment of non-metastatic gastric cancer with regard to type and extent of surgery, choice and sequence of chemotherapeutic agents, and use of radiation therapy vary somewhat depending on geographic location. In the U.S., until recently adjuvant chemo-radiation with fluoropyrimidines was most commonly used based on the INT0116 trial (2), while in Europe a perioperative approach (3) is favored and in East Asia patients mostly are treated with adjuvant chemotherapy alone (4). Also, there is heterogeneity and lack of consents regarding the optimal extent for lymph node dissection during gastrectomy (5-7). There is a paucity of literature concerning the direct comparison of various practices since most pivotal trials compared multimodality treatment to surgery alone (1-4). More recently, the FLOT-4 trial showed superior outcomes with a taxane containing perioperative triplet chemotherapy regimen compared to the anthracycline containing regimen established in the MAGIC trial (8). However, trials directly comparing chemotherapy alone to an intensified regimen on chemotherapy and radiation have been negative so far (9-11). To determine how variability in treatment practices affects patient outcomes, we conducted a retrospective study in patients with gastric cancer treated at five University of California (UC) medical centers. Here we present the results from one center.

\section{Methods}

\section{Study cohort}

This study was approved by the Institutional Review Board at the University of California in Irvine prior to the collection of data (approval \#11846). The study cohort which was retrospectively identified from electronic databases included patients diagnosed with gastric or gastroesophageal adenocarcinoma who underwent gastrectomy at one center from 2010-2017.

\section{Data collection}

We gathered retrospective data from UC electronic health records and California Cancer Registry databases. UC electronic health records and California Cancer Registry data were linked by patient identifiers in order to obtain more complete information about patients' treatment and followup. The UC electronic health records included demographics (age, race/ethnicity, and gender), diagnosis (ICD-9, ICD-10), procedure codes (ICD-10, CPT), laboratory tests and results, drugs, outpatient visits, and inpatient admissions. The California Cancer Registry data included tumor characteristics (stage, histology), surgical characteristics (technique, lymph node recovery), and chemotherapy characteristics (administration, regimens, completion status). We conducted chart reviews to validate patient outcomes.

\section{Statistical methods}

Descriptive statistics such as percentage, mean, and standard deviation were used to summarize patient demographic, clinical, tumor, surgical, and chemotherapy characteristics. To determine significant predictors of patient outcomes, only variables which temporally preceded the outcomes were included in the regression models as predictors. First, we performed univariate regression analyses in which one independent variable was included in the regression model at a time. Then we performed multivariate regression analyses in which we included the predictors that was found to be statistically significant at $\mathrm{P}$ value $<0.05$ in the univariate analyses. Correlations among the predictors were assessed before being considered in the multivariate analyses.

Cox regression models with proportional hazard distribution were performed to determine the predictors of cancer recurrence and death. The unit of analysis was a patient. The dependent variable was the time from gastrectomy to cancer recurrence (or death). For patients who had never had recurrence (or death) or were lost to follow up, the time was censored by their last visit. The independent variables included patient demographic, clinical, tumor, surgical, and chemotherapy characteristics. Hazard ratio was used to determine significant predictors at 
significance level $<5 \%$. A hazard ratio of value greater than 1 indicated that one group of patients was at greater risk of recurrence (or death) than the other group; a hazard ratio of value less than 1 indicated lower risk; and a hazard ratio of value equal to 1 indicated equal risk.

Logistic regression models were used to determine predictors of positive resection margins and hospitalization. The unit of analysis was a patient. The dependent variable was an indicator whether a patient had positive resection margins (or hospitalization within 6 months after gastrectomy). The independent variables included patient demographic, clinical, tumor, surgical, and chemotherapy characteristics. Odds ratio was used to determine significant predictors of hospitalization at significance level $<5 \%$.

\section{Results}

Patient demographic, clinical, tumor, chemotherapy, radiation therapy, and surgical characteristics are shown in Table 1.

\section{Demographic characteristics}

One hundred and sixteen patients fulfilled eligibility and were included. Their age at diagnosis ranged from 26 to 88 years, with the mean of 65.7 years $(\mathrm{SD}=11.6)$. About $65.5 \%$ were male. The most common ethnicities were Asian $(44.0 \%)$ and Caucasian (37.9\%).

\section{Clinical characteristics}

About $43.1 \%$ of the patients smoked or drank alcohol on a regular basis; $7.8 \%$ experienced significant weight loss at the time of cancer diagnosis; $8.6 \%$ had a history of cancer other than gastric cancer; and $55.2 \%$ of the patients had at least one comorbidity.

\section{Tumor characteristics}

\section{Anatomical location}

About $31.9 \%$ of the tumors were located in the esophagus and junction; $47.4 \%$ in the stomach body; and $20.7 \%$ in the antrum, pylori, and duodenum.

\section{Pathological stage}

About $41.4 \%$ were locoregional (i.e., pT4 or $\mathrm{pN} 1+$ ) while $58.6 \%$ were localized (i.e., p $\mathrm{T} 1-3$ and $\mathrm{pN}$ ).

\section{Tumor size}

About $40.5 \%$ of the tumors were small $(<2 \mathrm{~cm}) ; 27.6 \%$ were medium $(2-4 \mathrm{~cm}) ; 21.6 \%$ were large $(>4 \mathrm{~cm})$; and $10.3 \%$ of the tumors had missing size. The larger the tumor size, the higher the $\mathrm{T}$ and $\mathrm{N}$ stages $(\mathrm{P}=0.0068)$.

\section{Histology}

About $41.4 \%$ of the tumors were diffuse; $27.6 \%$ were intestinal; $12.0 \%$ were mixed type; and $19.0 \%$ were unknown histology. Diffuse histology were more common among tumors located in the stomach than in the esophagus (52.0\% vs. $19.0 \%, \mathrm{P}=0.0008$ ) and more prevalent among tumors with pT4 than pT1-3 (80.0\% vs. $40.0 \%, \mathrm{P}=0.0140)$.

\section{Chemotherapy and radiation therapy}

About $51.7 \%$ of the patients received chemotherapy. Among the chemotherapy recipients, about $26.7 \%$ received neoadjuvant only, $38.3 \%$ received adjuvant only, and $35.0 \%$ received perioperative chemotherapy. Only 65.0\% completed their required chemotherapy courses. Last but not least, about $19.0 \%$ of the patients received radiation therapy.

\section{Surgery}

Gastrectomy included laparoscopic (94.8\%) and open surgery (5.2\%). Total gastrectomy was performed in $12.9 \%$ of the patients, more frequently in higher stages: $4 \%$ of pT $1,0 \%$ in $\mathrm{pT} 2,23 \%$ in pT3, and $50 \%$ in $\mathrm{pT} 4(\mathrm{P}<0.0001)$. About $24.1 \%$ of the gastrectomy cases had $<15$ recovered lymph nodes; $52.6 \%$ had $15-29$ recovered lymph nodes; and $23.3 \%$ had $30+$ recovered lymph nodes.

\section{Outcomes}

Clinical outcomes are summarized in Table 2.

\section{Predictors of cancer recurrence}

After a median follow-up time of 19 months after gastrectomy, $16 \%$ of patients had cancer recurrence. Table 3 shows the predictors of cancer recurrence. In univariate analysis, we found several significant predictors of cancer recurrence which included race (non-Asian vs. Asian: hazard ratio $\mathrm{HR}=4.3$, 95\% CI: $1.3-14.9, \mathrm{P}=0.0196$ ), significant weight loss (yes vs. no: $\mathrm{HR}=5.2,95 \% \mathrm{CI}: 1.7-16.0, \mathrm{P}=0.0038$ ), pathological stage (loco-regional vs. localized stage: $\mathrm{HR}=10.8$, 
Table 1 Demographic, clinical, tumor, chemotherapy, radiation, and surgical characteristics

\begin{tabular}{|c|c|}
\hline Variables & $\begin{array}{c}\text { Descriptive } \\
\text { statistics }(\mathrm{N}=116)\end{array}$ \\
\hline \multicolumn{2}{|l|}{ Demographics } \\
\hline $\begin{array}{l}\text { Age at diagnosis, mean } \pm \text { SD [range] } \\
\text { (years) }\end{array}$ & $65.7 \pm 11.6[26-88]$ \\
\hline \multicolumn{2}{|l|}{ Sex $(\%)$} \\
\hline Male & 65.5 \\
\hline Female & 34.5 \\
\hline \multicolumn{2}{|l|}{ Race/ethnicity (\%) } \\
\hline Asian & 44.0 \\
\hline Caucasian & 37.9 \\
\hline Hispanic & 15.5 \\
\hline African American & 0.9 \\
\hline Others & 1.7 \\
\hline \multicolumn{2}{|l|}{ Clinical characteristics } \\
\hline \multicolumn{2}{|l|}{ Smoking/alcohol (\%) } \\
\hline Yes & 43.1 \\
\hline No or unknown & 56.9 \\
\hline \multicolumn{2}{|l|}{ Significant weight loss (\%) } \\
\hline Yes & 7.8 \\
\hline No or unknown & 92.2 \\
\hline \multicolumn{2}{|l|}{ History of cancer (\%) } \\
\hline Yes & 8.6 \\
\hline No or unknown & 91.4 \\
\hline \multicolumn{2}{|l|}{ Number of comorbidities (\%) } \\
\hline 0 & 44.8 \\
\hline $1-2$ & 19.0 \\
\hline $3+$ & 36.2 \\
\hline \multicolumn{2}{|l|}{ Tumor characteristics } \\
\hline \multicolumn{2}{|l|}{ Anatomic location (\%) } \\
\hline Esophagus/Junction & 31.9 \\
\hline Stomach body & 47.4 \\
\hline Antrum/pylori/duodenum & 20.7 \\
\hline
\end{tabular}

Table 1 (continued)
Table 1 (continued)

\begin{tabular}{|c|c|}
\hline Variables & $\begin{array}{c}\text { Descriptive } \\
\text { statistics }(N=116)\end{array}$ \\
\hline \multicolumn{2}{|l|}{ pT stage (\%) } \\
\hline 1 & 44.8 \\
\hline 2 & 16.4 \\
\hline 3 & 30.2 \\
\hline 4 & 8.6 \\
\hline \multicolumn{2}{|l|}{ pN stage (\%) } \\
\hline 0 & 61.2 \\
\hline 1 & 21.5 \\
\hline 2 & 6.9 \\
\hline 3 & 10.3 \\
\hline \multicolumn{2}{|l|}{ Pathological stage (\%) } \\
\hline Loco-regional (pT4 or pN1+) & 41.4 \\
\hline Localized (pT1-3 \& pN0) & 58.6 \\
\hline \multicolumn{2}{|l|}{ Tumor size (\%) } \\
\hline Small $(<2 \mathrm{~cm})$ & 40.5 \\
\hline Medium (2-4 cm) & 27.6 \\
\hline Large $(>4 \mathrm{~cm})$ & 21.6 \\
\hline Missing data & 10.3 \\
\hline \multicolumn{2}{|l|}{ Cell type (\%) } \\
\hline Diffuse & 41.4 \\
\hline Intestinal & 27.6 \\
\hline Mixed & 12.0 \\
\hline Unknown & 19.0 \\
\hline \multicolumn{2}{|c|}{ Diffuse histology by anatomical location (\%) } \\
\hline Esophagus & 19.0 \\
\hline Stomach & 52.0 \\
\hline \multicolumn{2}{|l|}{ Diffuse histology by T stage (\%) } \\
\hline pT4 & 80.0 \\
\hline pT1-3 & 40.0 \\
\hline \multicolumn{2}{|l|}{ Chemotherapy } \\
\hline \multicolumn{2}{|l|}{ Receipt of chemotherapy (\%) } \\
\hline Yes & 51.7 \\
\hline No & 48.3 \\
\hline
\end{tabular}

Table 1 (continued) 
Table 1 (continued)

\begin{tabular}{|c|c|}
\hline Variables & $\begin{array}{c}\text { Descriptive } \\
\text { statistics }(\mathrm{N}=116)\end{array}$ \\
\hline \multicolumn{2}{|c|}{$\begin{array}{l}\text { Administration among chemotherapy } \\
\text { receivers }(n=60)(\%)\end{array}$} \\
\hline Neoadjuvant only & 26.7 \\
\hline Adjuvant only & 38.3 \\
\hline Perioperative & 35.0 \\
\hline \multicolumn{2}{|c|}{$\begin{array}{l}\text { Agents among chemotherapy receivers } \\
(n=60)(\%)\end{array}$} \\
\hline Multi-agent & 86.7 \\
\hline Single agent & 13.3 \\
\hline \multicolumn{2}{|c|}{$\begin{array}{l}\text { Completion status among chemotherapy } \\
\text { receivers }(n=60)(\%)\end{array}$} \\
\hline Completed & 65.0 \\
\hline In progress/not completed & 35.0 \\
\hline \multicolumn{2}{|l|}{ Radiation therapy } \\
\hline \multicolumn{2}{|l|}{ Receipt of radiation therapy (\%) } \\
\hline Yes & 19.0 \\
\hline No & 81.0 \\
\hline \multicolumn{2}{|l|}{ Surgery } \\
\hline \multicolumn{2}{|l|}{ Surgical technology (\%) } \\
\hline Open & 5.2 \\
\hline Laparoscopic & 94.8 \\
\hline \multicolumn{2}{|l|}{ Surgical type (\%) } \\
\hline Total & 12.9 \\
\hline Partial & 87.1 \\
\hline \multicolumn{2}{|c|}{ Number of recovered lymph nodes (\%) } \\
\hline$<15$ & 24.1 \\
\hline $15-29$ & 52.6 \\
\hline $30+$ & 23.3 \\
\hline
\end{tabular}

95\% CI: 3.1-37.3, $\mathrm{P}=0.0002$ ), resection margin (positive vs. negative: $\mathrm{HR}=3.3,95 \% \mathrm{CI}: 1.1-9.9, \mathrm{P}=0.0363$ ), surgery type (total vs. partial: $\mathrm{HR}=6.6,95 \% \mathrm{CI}: 2.1-21.0, \mathrm{P}=0.0014$ ), and perioperative chemotherapy (perioperative $v s$. none: HR =15.0, 95\% CI: 3.1-71.9, $\mathrm{P}=0.0007)$. However, in multivariate analysis, the only significant predictor of cancer recurrence was pathological stage (loco-regional vs. localized stage: $\mathrm{HR}=7.0$, 95\% CI: 1.3-37.1, $\mathrm{P}=0.0228)$.
Table 2 Outcomes

\begin{tabular}{|c|c|}
\hline Variables & $\begin{array}{c}\text { Descriptive statistics } \\
\qquad(\mathrm{N}=116)\end{array}$ \\
\hline \multicolumn{2}{|l|}{ Primary outcomes } \\
\hline \multicolumn{2}{|c|}{ Cancer recurrence* $(\%)$} \\
\hline Distant recurrence & 12.1 \\
\hline Local recurrence & 4.3 \\
\hline None & 83.6 \\
\hline \multicolumn{2}{|l|}{ Death$^{*}(\%)$} \\
\hline Dead & 19.8 \\
\hline Alive & 80.2 \\
\hline \multicolumn{2}{|l|}{ Secondary outcomes } \\
\hline \multicolumn{2}{|c|}{ Positive resection margins (\%) } \\
\hline Yes & 8.6 \\
\hline No & 91.4 \\
\hline \multicolumn{2}{|c|}{$\begin{array}{l}\text { Hospital admission within } 6 \text { months } \\
\text { after gastrectomy }(\%)\end{array}$} \\
\hline Yes & 21.6 \\
\hline No & 78.4 \\
\hline \multicolumn{2}{|c|}{ Number of admissions per patient } \\
\hline Mean \pm SD & $1.4 \pm 0.8$ \\
\hline Median [range] & $1[1-4]$ \\
\hline \multicolumn{2}{|c|}{ Total length of stay (days) } \\
\hline Mean \pm SD & $10.2 \pm 14.7$ \\
\hline Median [range] & $7[1-74]$ \\
\hline
\end{tabular}

\section{Predictors of death}

After a median follow-up time of 19 months after gastrectomy, $20 \%$ of patients had died. Table 4 shows the predictors of death. In multivariate analysis, the only significant predictors of death were pathological stage (loco-regional vs. localized stage: $\mathrm{HR}=3.3,95 \% \mathrm{CI}: 1.3-8.6, \mathrm{P}=0.0160)$.

\section{Predictors of positive resection margins}

Positive resection margins were seen in $9 \%$ of the patients. Table 5 shows the predictors of positive resection margins. Histology was the only significant predictor of positive resection margins: patients who had tumors with diffuse 
Table 3 Predictors of cancer recurrence

\begin{tabular}{|c|c|c|c|c|}
\hline Predictors & \multicolumn{2}{|l|}{ Univariate } & \multicolumn{2}{|l|}{ Multivariate } \\
\hline Age at diagnosis (65+ vs. younger) & $0.7(0.3-1.8)$ & 0.4830 & & \\
\hline Sex (male vs. female) & $0.8(0.3-2.0)$ & 0.6134 & & \\
\hline \multicolumn{5}{|l|}{ Clinical characteristics } \\
\hline Smoking/alcohol (yes vs. no) & $1.6(0.6-4.0)$ & 0.2988 & & \\
\hline Significant weight loss (yes vs. no/unknown) & $5.2(1.7-16.0)$ & 0.0038 & $2.2(0.7-7.6)$ & 0.2013 \\
\hline Anatomical location (esophagus vs. stomach) & $1.3(0.5-3.3)$ & 0.5663 & & \\
\hline Pathological stage (loco-regional vs. localized) & $10.8(3.1-37.3)$ & 0.0002 & $7.0(1.3-37.1)$ & 0.0228 \\
\hline Tumor size (large vs. small/med/unknown) & $2.4(0.9-6.4)$ & 0.0795 & & \\
\hline Cell type (diffuse vs. intestinal/unknown) & $2.2(0.9-5.5)$ & 0.0874 & & \\
\hline \multicolumn{5}{|l|}{ Surgery } \\
\hline Resection margin (Positive vs. Negative) & $3.3(1.1-9.9)$ & 0.0363 & $1.6(0.5-5.1)$ & 0.4627 \\
\hline Number of recovered lymph nodes (<15 vs. $15+)$ & $1.8(0.5-4.6)$ & 0.2046 & & \\
\hline
\end{tabular}

histology were 6.6 times more likely to have positive resection margins than patients with intestinal, mixed, or unknown histology (OR =6.6, 95\% CI: 1.3-32.6, $\mathrm{P}=0.0207)$.

\section{Predictors of hospitalization}

Hospitalization within 6 months of gastrectomy was seen in $22 \%$ of the patients with a mean length of stay of 10 ( \pm 15 days). Table 6 shows the predictors of hospitalizations. Perioperative chemotherapy was the only significant predictor of re-hospitalization within 6 months after gastrectomy. Patients who received perioperative chemotherapy were 3.5 times more likely to be rehospitalized than those without chemotherapy $(\mathrm{OR}=3.5$, 95\% CI: $1.0-11.7, \mathrm{P}=0.0415$ ).

\section{Discussion}

The aim of the current single institution study was to determine prognostic factors for patients with nonmetastatic gastric cancer treated with modern multimodality regimens. We observed that there was little 
Table 4 Predictors of death

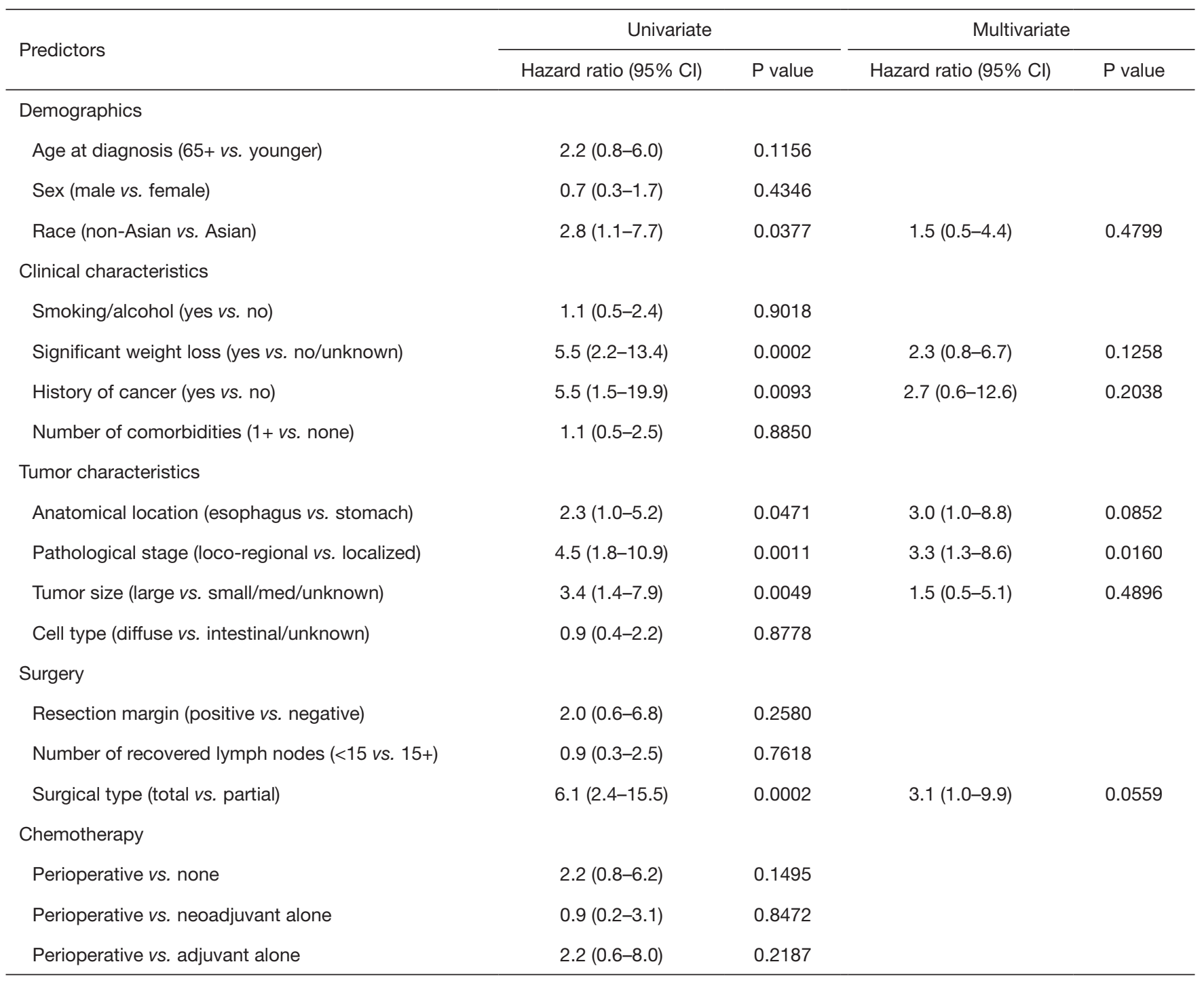

variation in surgical technique since the majority of patients underwent laparoscopic gastrectomy performed by one surgeon. However, there was some variation in chemotherapy administration with similar numbers of patients receiving neoadjuvant, adjuvant, and perioperative chemotherapy.

Despite a heterogeneous population with a range of different demographics and tumor characteristics, the only significant predictor of recurrence and death in multivariate analysis was the pathologic stage. Our findings are consistent with available literature highlighting the prognostic significance of pathologic stage in resected gastric cancer $(12,13)$. Importantly, the observed correlation between tumor extent and survival was dichotomous; that is, the hazard ratios for recurrence and death did not increase gradually with increasing TNM stage, as previously shown (14), but appeared to solely distinguish loco-regional stages (pT4, $\mathrm{pN} 1+$ ) from localized stages (pT1-3, pN0).

Our cohort included a higher proportion of poorly differentiated diffuse type adenocarcinomas compared to previous reports in the literature (12-16). These cases were associated with higher rates of positive resection margins, 
Table 5 Predictors of positive resection margins

\begin{tabular}{|c|c|c|c|c|}
\hline Predictors & \multicolumn{2}{|l|}{ Univariate } & \multicolumn{2}{|l|}{ Multivariate } \\
\hline \multicolumn{5}{|l|}{ Demographics } \\
\hline Age at diagnosis (65+ vs. younger) & $0.6(0.2-2.1)$ & 0.4149 & & \\
\hline Sex (male vs. female) & $1.3(0.3-5.1)$ & 0.7554 & & \\
\hline \multicolumn{5}{|l|}{ Clinical characteristics } \\
\hline Smoking/alcohol (yes vs. no) & $0.5(0.1-2.2)$ & 0.3874 & & \\
\hline Significant weight loss (yes vs. no/unknown) & $1.4(0.2-12.1)$ & 0.7824 & & \\
\hline History of cancer (yes vs. no) & $1.2(0.1-10.6)$ & 0.8710 & & \\
\hline Anatomical location (esophagus vs. stomach) & $1.5(0.4-5.6)$ & 0.5671 & & \\
\hline Pathological stage (loco-regional vs. localized) & $1.4(0.3-6.3)$ & 0.6547 & & \\
\hline Pathological stage (unknown vs. localized) & $3.0(0.5-17.9)$ & 0.2236 & & \\
\hline Tumor size (large vs. small/med/unknown) & $0.9(0.2-4.5)$ & 0.9007 & & \\
\hline Cell type (diffuse vs. intestinal/mixed/unknown) & $6.6(1.3-32.6)$ & 0.0207 & $6.6(1.3-32.6)$ & 0.0207 \\
\hline \multicolumn{5}{|l|}{ Chemotherapy } \\
\hline Neoadjuvant (yes vs. no) & $1.3(0.3-5.6)$ & 0.7383 & & \\
\hline
\end{tabular}

confirming available data (16). However, this did not translate into a decreased survival, potentially due to the cytotoxic effect of adjuvant chemotherapy (17).

With regards to adverse events associated with treatment, we found that patients who received perioperative chemotherapy were three times more likely to be hospitalized than those without chemotherapy. While survival does not appear to be negatively impacted, minimizing rehospitalization would positively affect patients' quality of life but also significantly reduce health care associated costs. Thus, based on our data, closer monitoring of patients undergoing perioperative chemotherapy within 6 months of surgery could be warranted.

The limitations of this study include retrospective nature, relatively small sample size, and single institution data. On the other hand, the data is derived from a contemporary patient cohort and thus might be more generalizable to current practices. The fact that we focused on a single institution with the majority gastrectomies done in a uniform fashion allowed us to minimize confounding factors in our analysis of prognostic factors. Also, the empirical effects of the significant predictors are large, with the hazard ratios and odds ratios of magnitudes from 3 to 7 .

Next steps would include validation of our findings in independent cohorts, including sites with higher variability in surgical approach (e.g., D1 versus D2 resection, etc.) to test whether surgical technique might compensate for some of the observation made in this current study. Finally, it would be interesting to integrate molecular data to the clinical variables to improve the performance of available prognostic factors for survival after surgery. 
Table 6 Predictors of hospitalization

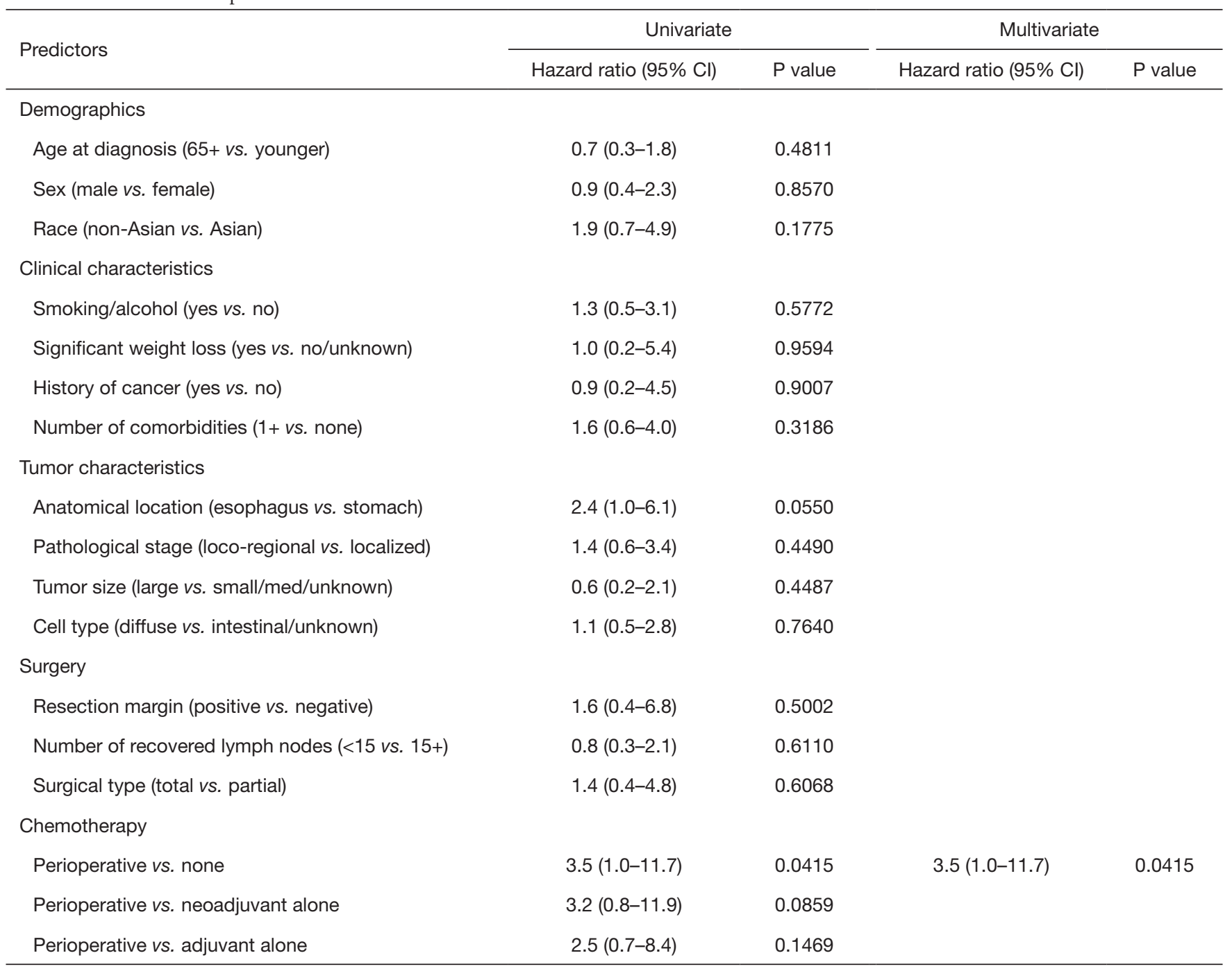

\section{Acknowledgements}

The authors thank Ms. Liz Adams, cancer registry manager at UCI Chao Family Comprehensive Cancer Center, who provided data and expertise that greatly assisted the research. Funding: This work was partially supported by grant UL1 TR001414 from the National Center for Advancing Translational Sciences, National Institutes of Health (NIH), through the Biostatistics, Epidemiology and Research Design Unit. The content is solely the responsibility of the authors and does not necessarily represent the official views of the NIH.

\section{Footnote}

Conflicts of Interest: All authors have completed the ICMJE uniform disclosure form (available at http://dx.doi. org/10.21037/jgo.2019.01.08). The authors have no conflicts of interest to declare.

Ethical Statement: The authors are accountable for all aspects of the work in ensuring that questions related to the accuracy or integrity of any part of the work are appropriately investigated and resolved. This study was approved by the Institutional Review Board at the University 
of California in Irvine prior to the collection of data (approval \# 11846).

Open Access Statement: This is an Open Access article distributed in accordance with the Creative Commons Attribution-NonCommercial-NoDerivs 4.0 International License (CC BY-NC-ND 4.0), which permits the noncommercial replication and distribution of the article with the strict proviso that no changes or edits are made and the original work is properly cited (including links to both the formal publication through the relevant DOI and the license). See: https://creativecommons.org/licenses/by-nc-nd/4.0/.

\section{References}

1. Ferlay J, Soerjomataram I, Ervik M, et al. GLOBOCAN 2012: Estimated Cancer Incidence and Mortality Worldwide in 2012 v1.0: IARC CancerBase No. 11. Lyon, France: International Agency for Research on Cancer, 2013.

2. Ychou M, Boige V, Pignon JP, et al. Perioperative chemotherapy compared with surgery alone for resectable gastroesophageal adenocarcinoma: an FNCLCC and FFCD multicenter phase III trial. J Clin Oncol 2011;29:1715-21.

3. Cunningham D, Allum WH, Stenning SP, et al. Perioperative chemotherapy versus surgery alone for resectable gastroesophageal cancer. $\mathrm{N}$ Engl J Med 2006;355:11-20.

4. Bang YJ, Kim YW, Yang HK, et al. Adjuvant capecitabine and oxaliplatin for gastric cancer after D2 gastrectomy (CLASSIC): a phase 3 open-label, randomised controlled trial. Lancet 2012;379:315-21.

5. Karpeh MS, Leon L, Klimstra D, et al. Lymph node staging in gastric cancer: is location more important than Number? An analysis of 1,038 patients. Ann Surg 2000;232:362-71.

6. Schwarz RE, Smith DD. Clinical impact of lymphadenectomy extent in resectable gastric cancer of advanced stage. Ann Surg Oncol 2007;14:317-28.

7. Songun I, Putter H, Kranenbarg EM, et al. Surgical treatment of gastric cancer: 15-year follow-up results of the randomised nationwide Dutch D1D2 trial. Lancet Oncol 2010;11:439-49.

8. Al-Batran SE, Homann N, Schmalenberg H, et al. Perioperative chemotherapy with docetaxel, oxaliplatin, and fluorouracil/leucovorin (FLOT) versus epirubicin, cisplatin, and fluorouracil or capecitabine (ECF/ECX) for resectable gastric or gastroesophageal junction
(GEJ) adenocarcinoma (FLOT4-AIO): A multicenter, randomized phase 3 trial. J Clin Oncol 2017;35:4004.

9. Park SH, Sohn TS, Lee J, et al. Phase III Trial to Compare Adjuvant Chemotherapy With Capecitabine and Cisplatin Versus Concurrent Chemoradiotherapy in Gastric Cancer: Final Report of the Adjuvant Chemoradiotherapy in Stomach Tumors Trial, Including Survival and Subset Analyses. J Clin Oncol 2015;33:3130-6.

10. Fuchs CS, Niedzwiecki D, Mamon HJ, et al. Adjuvant Chemoradiotherapy With Epirubicin, Cisplatin, and Fluorouracil Compared With Adjuvant Chemoradiotherapy With Fluorouracil and Leucovorin After Curative Resection of Gastric Cancer: Results From CALGB 80101 (Alliance). J Clin Oncol 2017;35:3671-7.

11. Cats A, Jansen EP, van Grieken NCT, et al. Chemotherapy versus chemoradiotherapy after surgery and preoperative chemotherapy for resectable gastric cancer (CRITICS): an international, open-label, randomised phase 3 trial. Lancet Oncol 2018;19:616-28.

12. Hamilton SR, Aaltonen LA. editors. Tumours of the Digestive System. In: World Health Organization Classification of Tumours: Pathology and Genetics. Lyon, France: IARC Press, 2000.

13. Kunz PL, Gubens M, Fisher GA, et al. Long-term survivors of gastric cancer: a California population-based study. J Clin Oncol 2012;30:3507-15.

14. Kikuchi S, Futawatari N, Sakuramoto S, et al. Comparison of staging between the old (6th edition) and new (7th edition) TNM classifications in advanced gastric cancer. Anticancer Res 2011;31:2361-5.

15. Shah MA, Khanin R, Tang L, et al. Molecular classification of gastric cancer: a new paradigm. Clin Cancer Res 2011;17:2693-701.

16. Pernot S, Voron T, Perkins G, et al. Signet-ring cell carcinoma of the stomach: Impact on prognosis and specific therapeutic challenge. World J Gastroenterol 2015;21:11428-38.

17. Morgagni P, Garcea D, Marrelli D, et al. Does resection line involvement affect prognosis in early gastric cancer patients? An Italian multicentric study. World J Surg 2006;30:585-9.

Cite this article as: Hoang T, Park M, Hiyama D, Dayyani F. Predictors of outcomes in patients with gastric cancer treated with contemporary multimodality strategies—a single institution experience. J Gastrointest Oncol 2020;11(2):411420. doi: 10.21037/jgo.2019.01.08 